\title{
Preparing for Planetary Surface Exploration by Measuring Habitat Dust Intrusion with Filter Tests During an Analogue Mars Mission
}

\author{
Ryan L. Kobrick, Ph.D. ${ }^{\text {a*}, ~ J u a n ~ H . ~ A g u i, ~ P h . D . ~}{ }^{\text {b }}$ \\ ${ }^{a}$ Department of Applied Aviation Sciences, Embry-Riddle Aeronautical University, 600 S Clyde Morris Blvd, \\ Daytona Beach, FL 32114, USA, kobrickr@erau.edu \\ ${ }^{\mathrm{b}}$ Thermal Systems and Transport Processes Branch, NASA Glenn Research Center, 21000 Brookpark Rd, Cleveland, \\ OH 44135, USA, juan.h.agui@nasa.gov \\ * Corresponding Author
}

\begin{abstract}
As humans venture deeper into space more issues related to operations will become apparent. While the perils of dust particles may not be widely recognized, it is one of the major issues astronauts will face on the surface of the Moon and Mars. Dust particles present a problem for both astronaut health and equipment as revealed during the Apollo era lunar surface missions. Dust particles cling to spacesuits and field gear, which upon ingress would begin circulating throughout the spacecraft or habitat. An astronaut's health is compromised by the dust particle's potential to embed in the lungs and cause respiratory illnesses. The extreme abrasiveness and granularity of the particles make it near impossible to completely shield a spacecraft or habitat from dust related damage. NASA's Glenn Research Center (GRC) collaborated with Crew 188 at the Mars Desert Research Station (MDRS) in Utah to measure how much dust entered the habitat during a series of extravehicular activities (EVAs), or surface excursions. A NASA GRC developed multistage filter system, coined the Scroll Filter System, was tested, for its effectiveness in removing dust that entered the airlock and habitat after the EVAs. An optical particle counter measured the ambient airlock particulates five times including: before the start of operations; after the crew left for EVA; in the middle of the EVA with the settled air; before the crew entered the airlock after EVA; and finally, after the crew simulated repressurization and suit brushing off in the airlock. Data was also collected in several of the working environment locations around MDRS and outside the habitat in the wind. Data collected from this research will help establish filter equipment for life support systems and prescribed operations for astronaut transition from a planetary surface into a desired clean habitat. Measurements may aid in updating a baseline expected dust load for a surface habitat and further facilitate the mitigation of astronaut's exposure to dust particles on the surface of celestial bodies.
\end{abstract}

\section{Keywords: Planetary Surface, Filter, Dust Contamination, Habitat, Operations, Simulation}

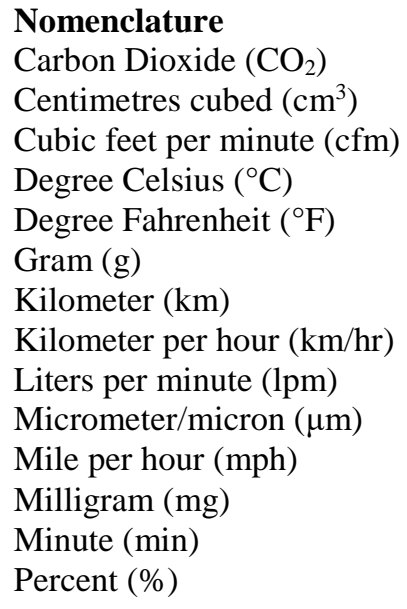

\section{Acronyms/Abbreviations}

Advanced Exploration Systems (AES)

Embry-Riddle Aeronautical University (ERAU)

Flashline Mars Arctic Research Station (FMARS)

Glenn Research Center (GRC)
High-efficiency particulate air (HEPA)

Innovative Partnership Program (IPP)

In-Situ Resource Utilization (ISRU)

International Space Station (ISS)

International Space University (ISU)

Mars Desert Research Station (MDRS)

National Aeronautics and Space Administration (NASA)

National Climatic Data Center (NCDC)

National Oceanic and Atmospheric Administration (NOAA)

Optical Particle Counter (OPC)

Particle size distribution (PSD)

Scroll Filter System (SFS)

Scroll Media Filter (SMF)

Spacesuit Utilization of Innovative Technology Laboratory (S.U.I.T. Lab)

United States Air Force (USAF)

Weather Bureau Army Navy (WBAN) 


\section{Introduction}

As humans venture deeper into space more issues related to operations will become apparent. While the perils of dust particles may not be widely recognized, it is one of the major issues astronauts will face on the surface of the Moon and Mars. Dust particles present a problem for both astronaut health and equipment as revealed during the Apollo era lunar surface missions $[1,2]$. Dust particles cling to spacesuits and field gear, which upon ingress would begin circulating throughout the spacecraft or habitat. An astronaut's health is compromised by the dust particle's potential to embed and scar the lungs and cause respiratory illnesses [3]. Ultrafine particles can even pass through the lung tissue and enter the bloodstream [4]. The extreme abrasiveness and granularity of the particles due to different erosion processes on the Moon make it near impossible to completely shield a spacecraft or habitat from dust related damage [5-9].

National Aeronautics and Space Administration's (NASA) Glenn Research Center (GRC) collaborated with Crew 188 at the Mars Desert Research Station (MDRS) in Utah to measure how much dust entered the habitat during a series of extravehicular activities (EVAs), or surface excursions. A NASA GRC developed multistage filter system, coined the Scroll Filter System (SFS), was tested, for its effectiveness in removing dust that entered the airlock and habitat after the EVAs. An optical particle counter (OPC) measured the ambient airlock particulates. Data was also collected in several of the working environment locations around MDRS and outside the habitat in the wind.

Data collected from this research will help establish filter equipment for life support systems and prescribed operations for astronaut transition from a planetary surface into a desired clean habitat. Measurements may aid in updating a baseline expected dust load for a surface habitat and further facilitate the mitigation of astronaut's exposure to dust particles on the surface of celestial bodies.

\subsection{Project Context}

To give context to how this research was created, a brief overview is provided here. The primary author, Professor Kobrick, is the Principal Investigator of the Embry-Riddle Aeronautical University (ERAU) Spacesuit Utilization of Innovative Technology Laboratory (S.U.I.T. Lab) in the Spaceflight Operations Program (Applied Aviation Sciences Department, College of Aviation). The S.U.I.T. Lab is focused on astronaut mobility and human performance for both intravehicular activities (IVAs) and EVAs and the relationship with mission operations. The ERAU S.U.I.T. Lab has been actively involved in several analogue space missions including EVA research during MDRS Crew 188 [10, 11].
As an alumnus to the International Space University (ISU), and having had previously analogue field experience at four MDRS two-week simulation rotations and a 100-operational-day simulation at the Flashline Mars Arctic Research Station (FMARS) on Devon Island, Nunavut, Canada in 2007, Kobrick was competitively selected as MDRS Crew 188's Commander by the Team ISU on Mars program (a cyclic program by volunteers). This provided an opportunity to link fieldwork into the classroom at ERAU and provide research projects for students to contribute in the S.U.I.T. Lab.

Kobrick's previous Ph.D. work with lunar dust abrasion was supported by the NASA's Graduate Student Research Program with summer research residency at NASA GRC working with the Dust Management Program and this paper's co-author Dr. Agui. Dr. Agui has been actively working on dust filtration and contamination control at NASA GRC including filter projects on the International Space Station (ISS). He has developed a novel (patent numbers $9,121,792$ and $10,078,036$ ) filtration system designed to reduce maintenance and provide regenerable filtration capacity. He has also developed and established a low-pressure filter test stand at the NASA GRC that simulates reduced cabin pressure environments and Martian atmospheric conditions [1215]. This combined background, and forecast on the future of human space exploration led to the work within.

\subsection{NASA Glenn Research Center Filtration Work}

The MDRS test data will be useful to NASA's mission planners working on future deep space missions. The data will provide key estimates on the levels of planetary dust exposure, and operational and design guidance to habitats and hardware during planetary surface missions. NASA's Advanced Exploration Systems (AES) invests in technologies that ensure crew safety and enable mission operation in deep space. AES focusses its developments in several functional areas, known as 'Domains'. One Domain is NASA's Life Support System project which advances the state of art of cabin air revitalization and water processing systems. Its aim is towards systems that save on mass, volume, and power, and that last the length of the mission with minimal maintenance. Advances take place through hardware development and testing, including flight demonstrations. Under this project, the GRC has developed and tested several filter system prototypes that provide regeneration and reduced maintenance operations [16,17]. The Scroll Filter System (SFS), initially developed under an Innovative Partnership Program (IPP) project between NASA and Aerfil, LLC, is comprised of four stages: a screen roll filter, an inertial impactor stage, an indexing (scrolling) 
media stage, and a high efficiency filter stage. Each stage targets a specific range of particle sizes that optimize the filtration and regeneration performance of the system.

Additionally, under the AES Foundational Systems domain, the In-Situ Resource Utilization (ISRU) project is developing atmospheric processing systems to harvest the mostly $\mathrm{CO}_{2}$ gaseous component of the Martian atmosphere. Particulate filters are required as the first conditioning element to remove Martian dust. Work is underway at NASA in this recent project to develop a sub-scaled and full-scale prototype of filter systems to effectively operate under the mission constraints and environment of a Mars surface mission. This includes media filter systems developed at GRC.

The filter system chosen for the MDRS tests, from several prototypes developed at NASA GRC, was one that was originally designed for an ISRU atmospheric processing application. This unit was available during the MDRS mission schedule and because of its relevance to ISRU applications was suitable for the MDRS mission. It was a smaller unit designed for an approximate flow rate of $0.2 \mathrm{cfm}$ (or $1500 \mathrm{~cm}^{3} / \mathrm{min}$ ). This prototype does not include a HEPA filter stage, and therefore contain only three out of the possible four stages of the SFS. Although somewhat under-sized to provide full filtration capacity in most of the workspaces in the MDRS, except for the airlock, it was expected to serve as a portable filtration unit providing temporary filtration over smaller region of the workspace.

A driving component of NASA filtration work is to quantify standards for the habitable volumes on the surface of Mars. NASA has provided a standard that limits the amount lunar dust exposure limit to the crew for particle sizes $<10 \mu \mathrm{m}$ to be below $0.3 \mathrm{mg} / \mathrm{m}^{3}$ for periodic exposures over a 6-month period [18]. This value can be used to inform the design of future Mars surface missions [19] and form a starting point for Martian surface dust exposure [20]. In addition, a study based on the Apollo missions provided estimates of the amount of dust that entered the lunar lander [21]. The derived value reported was of $227 \mathrm{~g} /$ suit-EVA with about $7 \%$ by mass of this amount of particles less than $10 \mu \mathrm{m}$ that can become airborne within the pressurized cabin environment. This value is considered a conservative estimate. For planetary exploration, these standards will have to account for the continuous dust contamination that transfers into the habitat from EVAs in addition to the common particulates, for example human skin or hair. Mars dust implications have previously been studied by Bos et al. [22] who observed similar dust quantities to the present results transferred into MDRS in 2003 during their study, which included
12 EVAs. Their worked showed that the dust contamination during their mission would far exceed the recommended maximum particulate concentration for a Mars habitat, a value that is 20 times greater than the requirement set for the ISS [22]. Industrial standards from mining industry facilities, military camps, or similar dirty environments would need to be further investigated to help set standards for Martian human spaceflight vehicle design.

\subsection{Mars Desert Research Station (MDRS) Habitat and Surrounding Utah Environment Overview}

The Mars Desert Research Station (MDRS) is located near Hanksville, Utah in a mudstone- and sandstone-rich environment that contains stratigraphy deposited in an ancient aquatic environment, and generally bears an uncanny resemblance to much of the Martian terrain. Since 2001, approximately 195 mission simulations have taken place at The Mars Society's facility, with the standard rotation lasting two-weeks. MDRS was established to better educate researchers, students and the general public about how humans can survive on the Red Planet [23]. The primary structure habitat, a.k.a. 'The Hab", layout is shown in Figure 1 and has endured several changes over the years, the most notable being the addition of various external structures including but not limited to greenhouses, telescopes, engineering sheds from basic fueling stations to an airstream workshop, and a large geodesic structure, or Science Dome. The configuration of the entire MDRS campus during this study is shown in Figure 2, where structures are connected by simulated pressurized tunnels, but are currently exposed to the Utah elements. The Hab is designed to accommodate a crew size of 6 , but has seen many permutations.

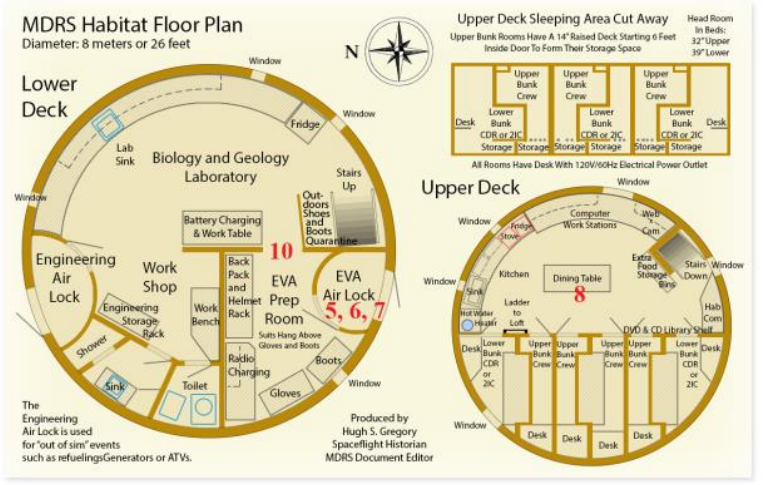

Figure 1: Primary habitat layout at MDRS. EVA filtration unit tests are indicated on the layout for Tests \#5 through 8 and \#10 and will be further explained in this paper [23]. 


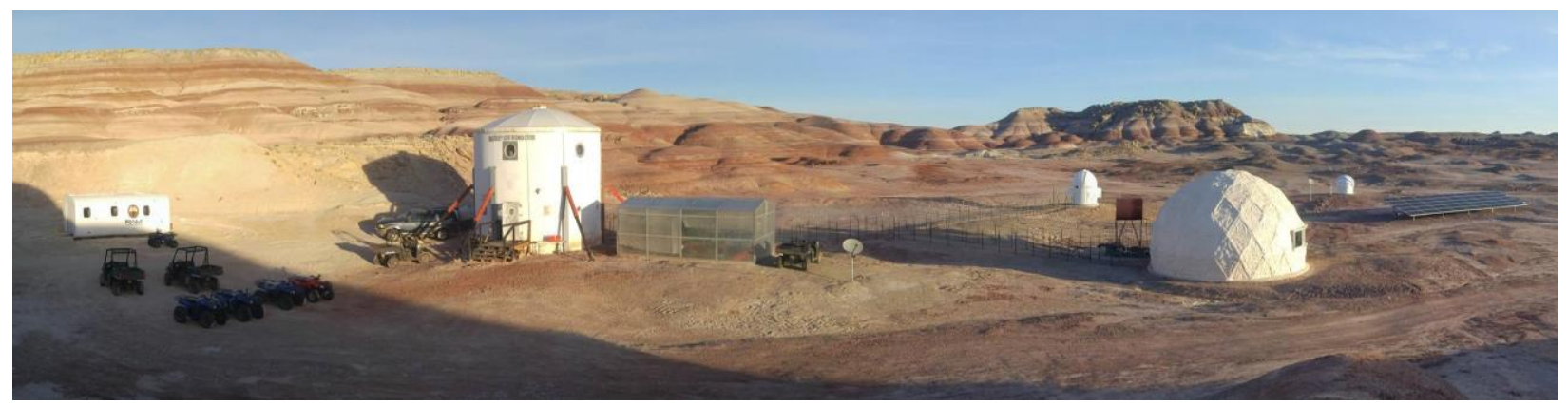

Figure 2: MDRS campus layout during Crew 188. The main Habitat is towards the middle-left. Science Dome on the right. The tunnels connecting the structures are not covered and exterior doors are all exposed to external weather.

The majority of EVA operations pass through the EVA Air Lock and into the EVA Prep Room, sometimes just called the spacesuit room. Previously, the Lower Deck of the Hab was used as the Biological and Geological Laboratory. Since that science lab work migrated to the Science Dome, the lower deck has been utilized for a variety of activities including suit donning and doffing, where the EVA Prep Room is primarily used for simulated spacesuit stowage and charging (see Figure 3 and Figure 4). The luxury of more habitable volume gives the crew more preparation space, but also comes with the cost of dust transport into more of the Lower Deck.

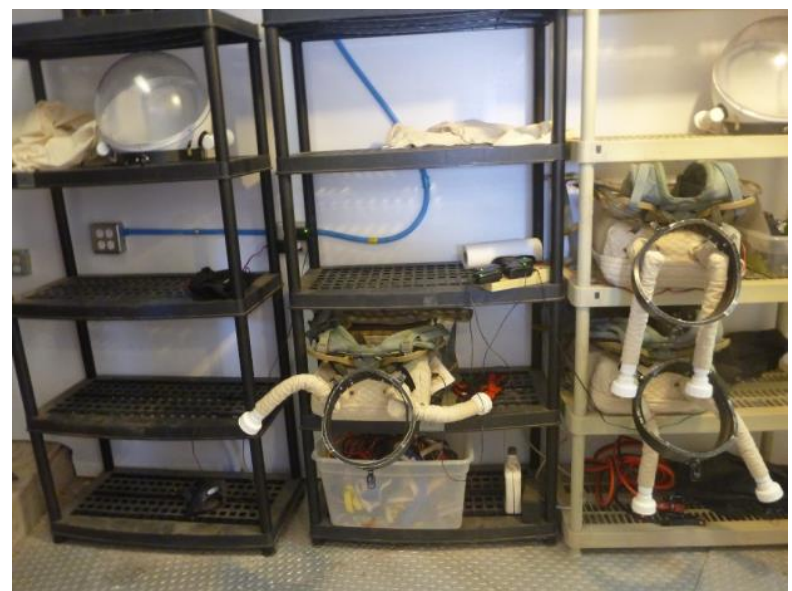

Figure 3: EVA Prep Room used primarily for storing simulated spacesuit EVA equipment in between uses. The crew passes through this room from the EVA Air Lock into the habitat Lower Deck to don/doff their gear.

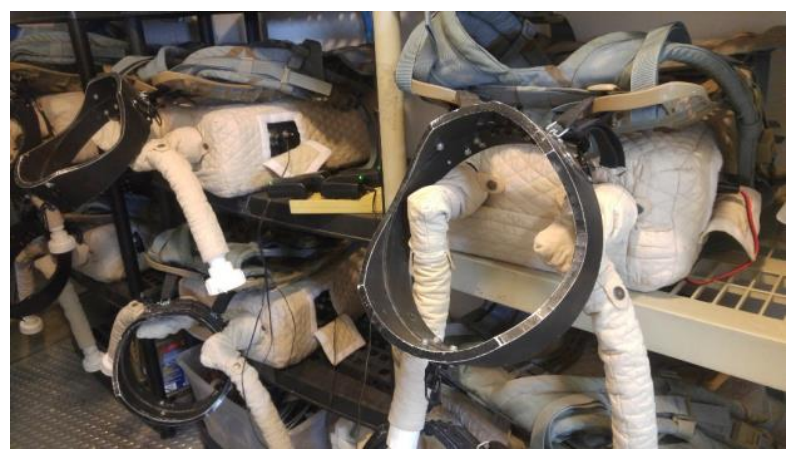

Figure 4: EVA Prep Room close up showing simulated spacesuits being charged in between EVAs.

Utah is an extremely dusty environment as a result of the friable sandstone, and dry desert conditions. Every room and every structure at MDRS has a notable layer of fine-grained dust particles (see Figure 5). As days pass by during a simulation, you can start to feel the grit between the keys of laptops and in port holes of devices. Most crews are diligent not to wear any outdoor shoes or layers inside the Hab, but dust finds a way. Dry air leads to electrostatic charging and transport of small particles as they cling from surfaceto-surface. Wet wipes are effective at cleaning surfaces, but that is a temporary solution. There is no internal ventilation in the structures of MDRS, so airflow can be stagnant and there are no filters to remove contaminants. On Mars, habitats will likely have ventilation with filtrations, such that particulate levels will be lower. But as seen during the lunar missions, depending on the EVA operations, equipment may need to be robust enough to be dirty, all the time. 


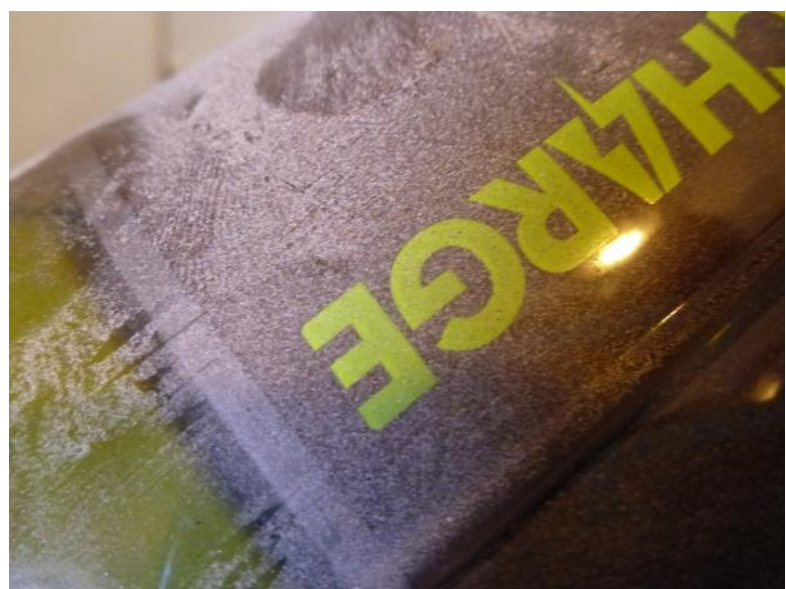

Figure 5: Dust coats everything in MDRS and it was very noticeable on the vacuum when the filter was loose. Fingerprints can be clearly distinguished.

\subsection{MDRS Crew 188 Mission Summary}

Team ISU on Mars took residency at MDRS from 27 January to February 10, 2018 as Crew 188. The third rotation of the program included a highly motivated group of scientists, engineers, thinkers, creators and innovators from around the world who hold graduate degrees from the ISU Masters and Space Studies Programs. The crew shares a passion for space research, engineering, the arts, mission design, operations, and exploration that formed a tightly bonded team of space adventurers through their MDRS experience.

The crew conducted over 10 investigations during their rotation that involved: industry partners such as Final Frontier Design (provided Thermal Micrometeoroid Garment gloves) and Monash Immersive Visualisation Platform (provided an Insta360 Pro Camera); academic instituions including ERAU, Florida Institute of Technology, and the University of South Australia; and government collaborations with NASA GRC, Kennedy Space Center ("Veggie" experiment designed by Orbital Technologies Corp.), and NASA Ames (Chlorophyll detecting devices by Robotics Everywhere LLC), as well as the Australia Council. The crew also took on the initiative of conducting professional social media engagemnt before, during and after their mission, which also included a live "Mars-2-Mars" video conference with the crew at AMADEE-18 in Oman who were simultaneouly in a Martian simulation.

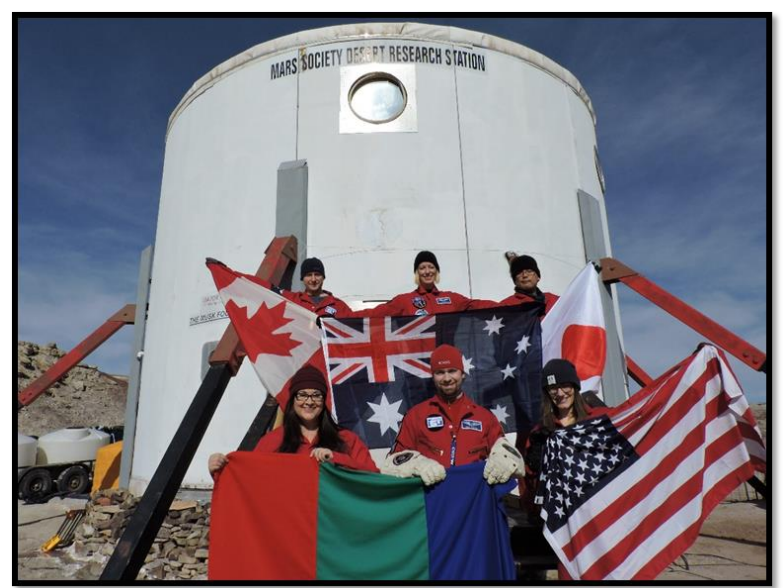

Figure 6: MDRS Crew 188 before starting the two-week simulation in front of the MDRS Hab.

Crew 188 conducted a total of 15 EVAs, totaling 33 hours and 46 minutes in the field, covering $139.9 \mathrm{~km}$ operating within a $6-\mathrm{km}$ radius zone [10]. This dust investigation commenced on EVA 007 after equipment unpacking and sufficient preparation with question and answer sessions via email for operational procedures.

\subsection{MDRS Test Objectives}

The preliminary design test objectives and driving questions of this investigation were:

1. to measure the amount of dust intrusion into the airlock after an EVA;

2. to measure the effectiveness of dust filtration after EVA return in airlock; and

3. to measure the effectiveness of dust filtration in work areas.

Additionally, the investigators wanted to attempt an accelerated investigation development timeline to test the feasibility of deploying equipment to an exploration location with similar communication constraints as a real interplanetary space mission. The minimal development and crew training would then serve as an analogy for mission support (or mission control) sending new equipment and instructions to a crew for science or maintenance. Another aspect of this mission constraint is the amount of crew training needed for a Mars mission that would be so extensive that some of the training may have to be done or refreshed in realtime during the mission. For example, a 3D printed device with setup instructions could be added to any mission profile as long as crew time can be allocated. In this example, generic training for astronauts could focus on $3 \mathrm{D}$ printer maintenance and circuit board assembly. Time must be allocated for the back and forth communication needed to clarify operational steps and possible pilot data analysis. 


\section{Testing Materials and Methodology}

\subsection{Key Equipment}

\subsubsection{Scroll Filter System (SFS)}

The Scroll Filter System (SFS) has been under development for several years at the NASA GRC. It was designed to provide conventional media filtration as well as novel inertial filtration techniques. The system also provides self-changing and regenerable capabilities. These features will be important to minimize operations and crew time for crewed deep space missions. The SFS prototype used at MDRS shown in Figure 7 is comprised of two main hardware modules.

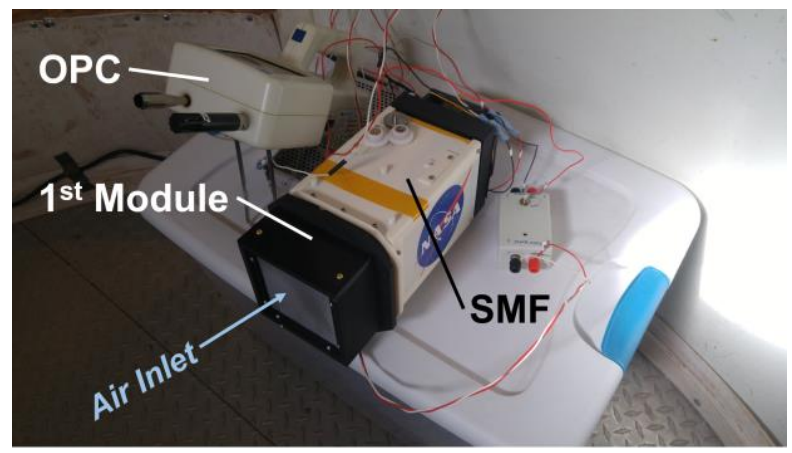

Figure 7: Scroll Filter System (center) with Optical Particle Counter (on left) located along airlock inner wall for sampling with the EVA crew.

The first module contains two stages of filtration. The first stage (black portion in Figure 7) is a screen filter which uses screen mesh material of specific mesh size opening. Its function is to capture large airborne debris. The second stage is an impactor pre-filter which uses inertial impaction through area reducing devices (e.g. orifice or slits) for separating and collecting particles several microns and larger on collection bands. The collection bands are regenerated by using a band conveying mechanism and a scrapper.

The larger module is the Scroll Media Filter (SMF). It is a media filter that provides multiple changes of the filter media inside the flow volume through a motorized scrolling or indexing mechanism. The loaded media is rolled up on one side of the filter to both contain and compactly store the loaded PM (white portion with sticker shown in Figure 7).

\subsubsection{Optical Particle Counter (OPC)}

The portable Optical Particle Counter (OPC) was deployed in the different work areas in order to characterize the dust environment. The work areas included the airlock (as seen in Figure 8), the EVA Prep Room (as seen in Figure 18), general Upper Deck Work Area (as seen in Figure 14), and the Science Dome (as seen in Figure 16). The OPC samples the surrounding air and provides measurements of particle sizes and number counts of the dust entrained in the sampled flow. The instrument provides the data in the form of particle size distributions (PSDs) of the dust. Total counts are calculated by the summing up particle counts in each size bin.

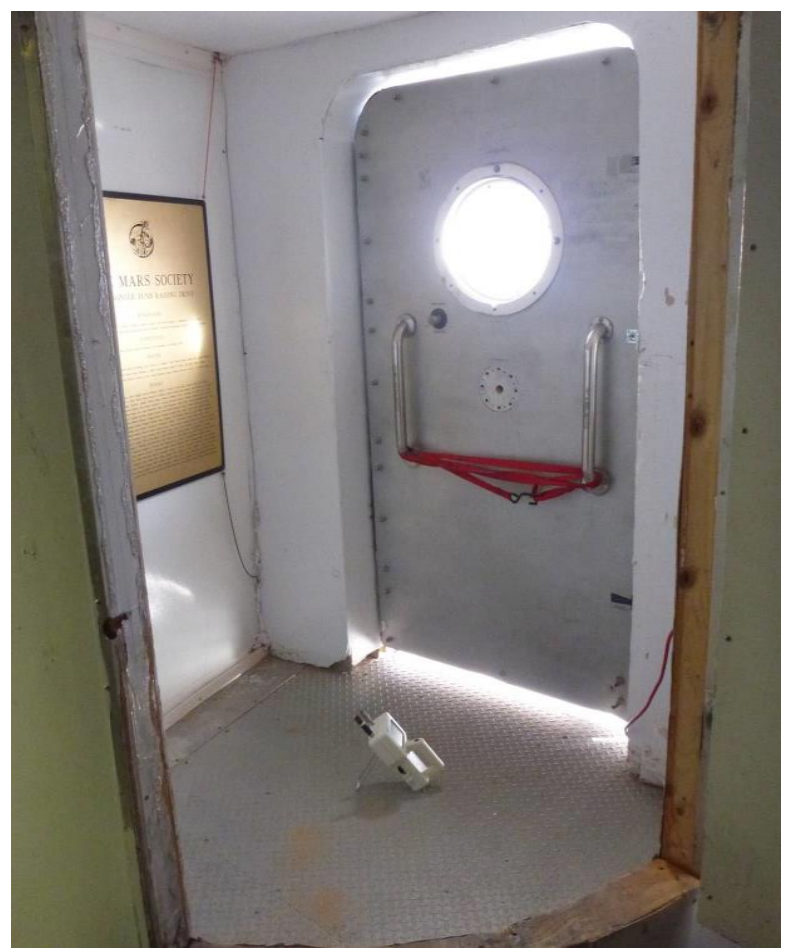

Figure 8: The OPC located central in MDRS airlock during sampling without the EVA crew.

\subsubsection{Vacuum Cleaner}

A standard household handheld portable vacuum cleaner was used to capture all dust transported into the EVA Air Lock by the EVA crew (as partially seen in Figure 5). A sheet of filter media was added within the HEPA stage of the vacuum for each test to examine at the fine particles (as seen in Figure 9).

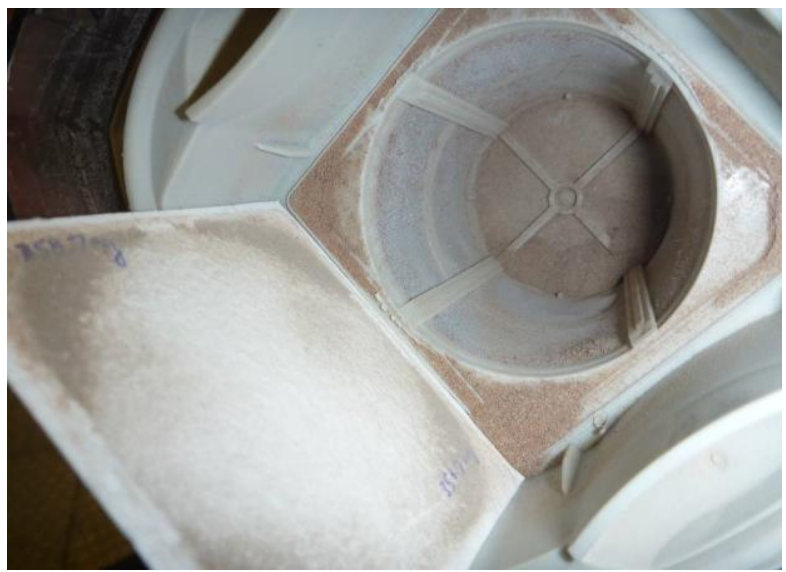

Figure 9: Vacuum filter with additional NASA filter after EVA \#14 airlock cleaning. 


\subsection{General Procedures and Tasks}

The following is an abbreviated procedures description summarizing the tasks associated with the 11 tests as summarized in Table 1 . Table 1 values show the recorded crew time minutes for each procedure step from recorded time stamps. Tests 2 through 7 were conducted before/during/after EVAs, Tests 8 through 10 were conducted in various work areas at MDRS, and Test 11 was conducted outdoors on a windy day at the end of the simulation.

Table 1: A combined view of the procedure tasks accomplished for each test with the total crew time for each step

\begin{tabular}{|c|c|c|c|c|c|c|c|c|c|c|}
\hline \multirow{2}{*}{$\begin{array}{c}\text { Test } \\
\# \\
\end{array}$} & \multirow[t]{2}{*}{ Event } & \multicolumn{8}{|c|}{ Procedure \# } & \multirow{2}{*}{$\begin{array}{c}\text { Test Totals } \\
(\mathrm{min})\end{array}$} \\
\hline & & I & II & III & IV & $\mathbf{V}$ & VI & VII & VIII & \\
\hline 1 & Setup & 60 & & & & & & & & 60 \\
\hline 2 & EVA 007 & & 25 & & & & & 25 & & 50 \\
\hline 3 & EVA 008 & & 25 & & & & & 25 & & 50 \\
\hline 4 & EVA 009 & & 25 & & & & & 27 & & 52 \\
\hline 5 & EVA 010 & & 25 & 30 & & & 5 & 19 & & 79 \\
\hline 6 & EVA 012 & & 25 & 10 & 10 & 20 & 5 & 16 & & 86 \\
\hline 7 & EVA 014 & & 25 & 10 & 11 & 11 & 5 & 28 & & 90 \\
\hline 8 & $\begin{array}{l}\text { Work Area - Upstairs } \\
\text { Work Area - Science }\end{array}$ & & 10 & 7 & 8 & 7 & 60 & & & 92 \\
\hline 9 & Dome & & 10 & 7 & 7 & 7 & 61 & & & 92 \\
\hline 10 & Work Area - EVA Room & & 15 & 6 & 6 & 10 & 63 & & & 100 \\
\hline 11 & Outdoor - Windy & & & & & & & & 142 & 142 \\
\hline I & Administrative emails & 120 & & & & & & & & 120 \\
\hline I & Packing Gear & 60 & & & & & & & & 60 \\
\hline & Task Totals (min) & 240 & 185 & 70 & 42 & 55 & 199 & 140 & 142 & 1073 \\
\hline
\end{tabular}

\section{Setup}

During the setup all equipment was unpacked and wires were connected for the filtration unit. Power and control switches were tested, and the screen media was changed.

\section{Optical Particle Counter (OPC) Measurements}

The OPC was charged for each use and run five times during the test EVAs: before the start of operations; after the crew left for EVA; in the middle of the EVA with the settled air; before the crew entered the airlock after EVA; and finally, after the crew simulated re-pressurization and suit brushing off in the airlock. The OPC was run twice during work area tests: before and after the filtration unit was run. Each OPC test point was obtained by running the OPC for 10 seconds at a flow rate of $2.8 \mathrm{lpm}$ a total of three times, corresponding to an average measurement with a sampled volume of $1444 \mathrm{~cm}^{3}$ taken over 30 seconds.

\section{Filtration Unit Screen Media Changing}

The screen media (or mesh screen) in the immediate inlet of the pre-filter stage of the SFS first module was replaced for each test. Each screen was weighted before deployment to MDRS and afterwards at NASA GRC.
IV. Filtration Unit Rubber Band Replacement

The four rubber bands located within the impactor filter stage of the SFS first module (after the inlet screen media mesh) were replaced for each test. Each rubber band was weighted before deployment to MDRS and afterwards at NASA GRC.

\section{Filtration Unit Scroll Media Advancement}

The pre-filter stage was removed to access the scroll media in between each test. The media was marked on both exposed ends with vertical lines including the test date and number. The scroll motor was activated to advance the media to unexposed media, followed by reassembly.

\section{Filtration Unit Activation}

The activation of the SFS filtration unit enabled the fan to draw environmental air into the complete device for the prescribed time.

\section{Vacuum Cleaning}

The vacuum was charged for each use within the airlock. An additional sheet of filter media was added within the vacuum filter cartridge in the vacuum collection cup. The vacuumed collected matter was placed in sample bags, labelled, and sent to NASA GRC for analysis. Each filter was weighted before deployment to MDRS and afterwards at NASA GRC. 


\section{Filtration Unit Outdoor Exposure}

The pre-filter stage SFS first module was removed to expose the SMF stage for outdoor exposure. The partial unit was fastened to the front staircase leg (as seen in Figure 20). The media was marked on both exposed ends with vertical lines including the test date and number.

\subsection{Testing Locations}

The testing locations were chosen to give a variety of habitable volume locations to gain insight to the PSDs of dust contamination for simulated astronauts.

The Upper Deck Work Area located outside of the crew state rooms is the primary dining area and most common evening work location. It has a high amount of traffic. Maintaining sanitation of a food preparation zone and high frequency location is important for maintaining crew health, especially in a long duration spaceflight mission.

The Science Dome is designated as the primary workspace for biological and geological experimentation from sample collection. Samples are inherently dirty; however, a clean room environment is critical for avoiding cross contamination. If life detection experiments were being conducted on the surface of Mars, equipment would be continually sterilized and the lab location would need to be treated more like a clean room to keep particulates to a minimum. The current configuration of the Science Dome does not include an airlock (as discussed further in Section 4.2.1.).

The EVA Prep Room in the Lower Deck is expected to have the next largest amount of dust contamination after the EVA Air Lock as equipment from the field is stored here (simulated spacesuits' jumpsuits and life support simulators, boots, gloves, gators, and other accessories). The transition from this room into the Lower Deck (former laboratory) was targeted for measurement as the crew would use the entire lower section for spacesuit donning and doffing.

\section{Results}

\subsection{Post-EVA Dust Transported and Vacuumed in} Habitat Airlock

Vacuum cleaning was performed to quantify the amount of dust transported into the habitat. Samples were sent back to NASA GRC as well as the additional filter sheets. The interior of the vacuum cup located before the HEPA filter is shown in Figure 9.

Table 2 compiles the mass quantities of dust collected in the main habitat airlock after each EVA. The dust was collected by vacuum cleaning over the airlock walls and floor. The portable vacuum cleaner incorporates three collection stages. Firstly, the inlet of the vacuum cleaner directly enters into a first stage collection cup where coarse particles are collected.
Then, the vacuumed flow enters a fine mesh cup shaped strainer (90 mesh). Lastly, the flow passes through a pleated HEPA cartridge. Additionally, a sheet of HEPA media was placed in front of the HEPA cartridge for sampling purposes, which was removed after each test and later weighed at NASA GRC. The data shows that the bulk of the dust, approximately $99 \%$, was collected in the vacuum cleaner's collection cup and in the strainer (screen filter) cup. The remaining approximate $1 \%$ of the particles, the smallest particles captured, were collected on the HEPA sheet.

Table 2: Dust collection from vacuum cleaning in the airlock after EVA.

\begin{tabular}{lcrrcc}
$\begin{array}{c}\text { Test } \\
\text { \# }\end{array}$ & $\begin{array}{c}\text { Vacuum } \\
\text { Cup } \\
(\mathbf{g})\end{array}$ & $\begin{array}{c}\text { Sheet } \\
\text { Filter } \\
(\mathbf{m g})\end{array}$ & $\begin{array}{c}\text { Total } \\
\text { Mass } \\
(\mathbf{g})\end{array}$ & $\begin{array}{c}\text { Vacuum } \\
\text { Cup } \\
\mathbf{\%}\end{array}$ & $\begin{array}{c}\text { Sheet } \\
\text { Filter } \\
\mathbf{\%}\end{array}$ \\
\hline $\mathbf{2}^{*}$ & 35.39 & 26.1 & 35.42 & 99.93 & 0.07 \\
$\mathbf{3}$ & 4.54 & 50.8 & 4.59 & 98.89 & 1.11 \\
$\mathbf{4}$ & 4.32 & 35.7 & 4.35 & 99.18 & 0.82 \\
$\mathbf{5}^{* *}$ & 11.66 & 33 & 11.70 & 99.72 & 0.28 \\
$\mathbf{6}^{\dagger}$ & 11.84 & 68 & 11.90 & 99.43 & 0.57 \\
$\mathbf{7}^{*}$ & 3.36 & 18.2 & 3.38 & 99.46 & 0.54 \\
\hline Totals & $\mathbf{7 1 . 1 1}$ & $\mathbf{2 3 1 . 8}$ & $\mathbf{7 1 . 3 4}$ & $\mathbf{9 9 . 6 8}$ & $\mathbf{0 . 3 2}$
\end{tabular}

*First EVA prior to general cleaning

** Dirty work during EVA (ran filter while in airlock)

†physical activity during EVA

†Dust generating ops during EVA

Figure 10 shows a micrograph, obtained with an optical microscope, of the one of the HEPA sheets used in the portable vacuum cleaner. It reveals the range of particle sizes that were collected in the last stage of vacuuming. The largest particle was about $4 \mu \mathrm{m}$ in the micrograph, and the smallest visible particles were close to $1 \mu \mathrm{m}$ in size.

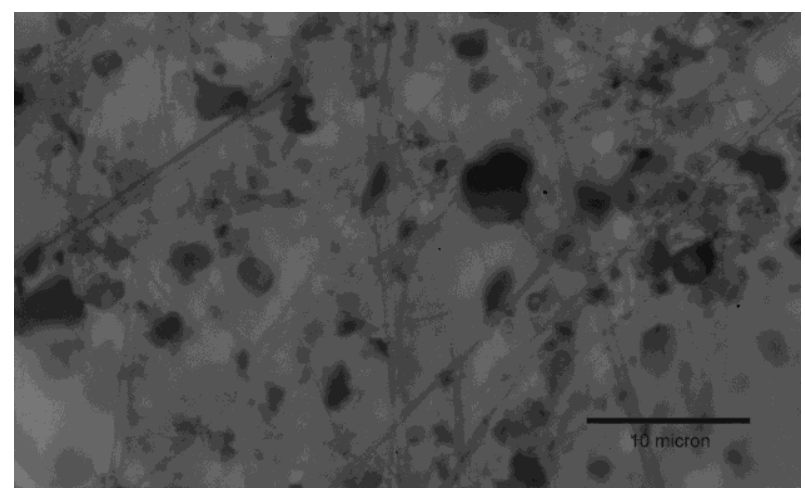

Figure 10: Micrograph of particle loading on HEPA sheet used with the vacuum cleaner (10 micron scale shown). 
The total amount of dust collected during each EVA varied with the activities performed by the crew. Since the first EVA took place during Test \#2 there was no generally cleaning of the airlock performed prior to this EVA, and consequently a large quantity of dust was collected during this test. Therefore, Test\# 2 was not considered in the subsequent analysis. Total dust counts ranged from $3.38 \mathrm{~g}$ to $11.9 \mathrm{~g}$ for Tests \#3 through \#7. The largest amount of dust that entered the airlock took place during Test \#5, while the smallest amount was brought back in Test \#7. The amount of dust in Tests \#5 and \#6 were significantly more than in the other tests. The amounts collected in Tests \#3 and \#4 were about the same and slightly above the smallest amount collected in Test \#7.

\subsection{Particle Counts of Airborne Dust}

Measurements of airborne dust particle size distributions (PSD's) were obtained using the OPC in various locations in order to assess the air quality induced by different crew activities. Baseline reference measurements were taken prior to various phases of activity, while subsequent measurements after the activities were obtained to show the change in particle counts. Section 2.2 (Procedure \#II) describes the timeline of OPC measurements.

\subsubsection{Dust Measurements Before Activities/Filtration}

Table 3 provides total particle counts before and during, or after, each activity for each test. Starting with the EVAs, the data show that the dust levels varied in the airlock on each day prior to the EVA. In fact, the baseline dust counts prior to the EVA tended to decrease with each consecutive EVA, with counts below 2000 after Test \#5 and up to Test \#7, the last EVA. After the crew entered the airlock upon returning from the EVA, the counts decreased slightly (if we discount Test \#2 for reasons specified in Section 3.1), except for Test \#5 where the counts almost doubled.

Tests \# 8 - 10 were linked with filtration activity in the various workspaces. The baseline particle counts prior to filtration are significantly larger than in the airlock. After filtration, the particle counts clearly dropped in all of the workspaces.

Figure 11 compares the PSDs of the airborne dust in the airlock, EVA Suit Room, and the general upstairs work area prior to activities. The distributions in the airlock and the Suit Room appear to be similar. However, the upstairs Work Area is shown to contain a greater quantity of particles in the in the $0.5 \mu \mathrm{m}$ to $2 \mu \mathrm{m}$ particle sizes. The distribution in the Science Dome, shown in Figure 12, shows exceedingly higher particle counts in all sizes. Also, the drop in particle counts in the Science Dome occurs at the $1 \mu \mathrm{m}$ size rather than at $0.3 \mu \mathrm{m}$ as it did in the other three work areas.
Table 3: Total particle counts obtained with Optical Particle Counter

\begin{tabular}{|c|c|c|c|}
\hline $\begin{array}{c}\text { Test } \\
\#\end{array}$ & Activity & $\begin{array}{l}\text { Total Particle } \\
\text { counts before } \\
\text { EVA and/or } \\
\text { running filter }\end{array}$ & $\begin{array}{l}\text { Total Particle } \\
\text { counts after } \\
\text { EVA and/or } \\
\text { running filter }\end{array}$ \\
\hline $2 *$ & EVA 007 & 1899.2 & 2565.2 \\
\hline 3 & EVA 008 & 5175.2 & 4869.6 \\
\hline 4 & EVA 009 & 3118.4 & 1874.8 \\
\hline $5 * *$ & $\begin{array}{l}\text { EVA } 010 \\
\text { (with } \\
\text { filtration) }\end{array}$ & 1740.2 & 3052.2 \\
\hline $6 \dagger$ & EVA 012 & 825 & 1344.4 \\
\hline $7 \dagger$ & EVA 014 & 1239 & 2290.6 \\
\hline 8 & $\begin{array}{l}\text { Work Area } \\
\text { - Upstairs } \\
\text { (filtration) }\end{array}$ & 2522.8 & 2009 \\
\hline 9 & $\begin{array}{l}\text { Work Area - } \\
\text { Science } \\
\text { Dome } \\
\text { (filtration) }\end{array}$ & 54721.4 & 43640.6 \\
\hline 10 & $\begin{array}{l}\text { Work Area - } \\
\text { EVA Room } \\
\text { (filtration) }\end{array}$ & 1743.4 & 1034.8 \\
\hline \multicolumn{4}{|c|}{$\begin{array}{l}\text { *First EVA prior to general cleaning } \\
* * \text { Dirty work during EVA } \\
\text { †physical activity during EVA } \\
\text { †Dust generating ops during EVA }\end{array}$} \\
\hline
\end{tabular}

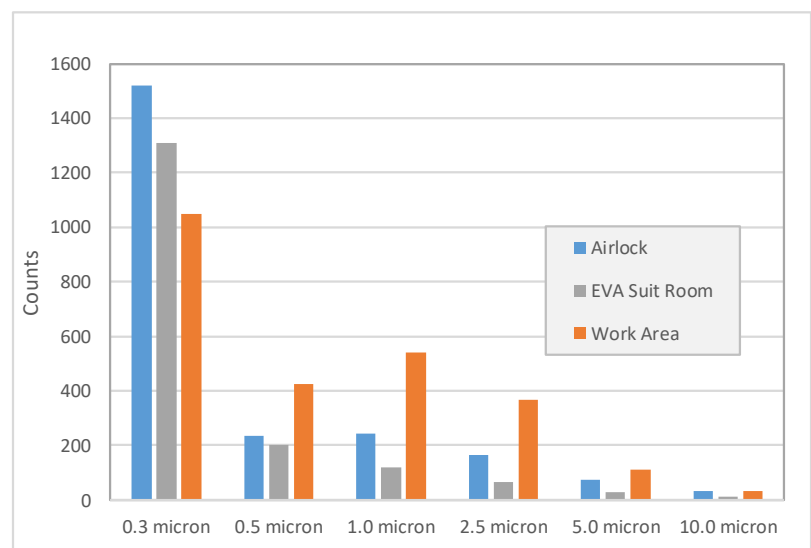

Figure 11: Particle Size Distribution from OPC prior to activities ("Work Area" refers to Upper Deck). 


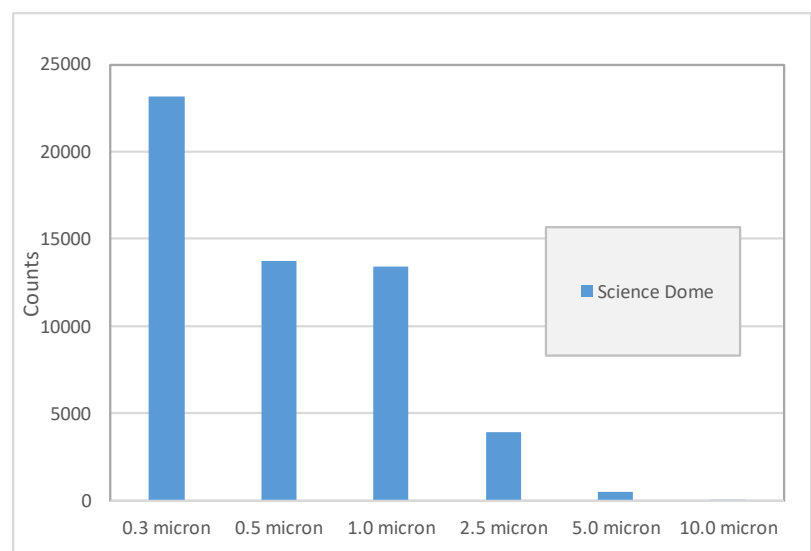

Figure 12: Particle Size Distribution from Optical Particle Counter prior to activities in the Science Dome.

\subsubsection{EVA Dust PSD}

As mentioned in Section 2.2 the OPC was used on five occasions during the different phases of the EVA. For the most part, the distributions taken prior to the EVA, before and in the middle of the EVA operations were similar to the distributions obtained when the crew returned from the EVA but before entering the airlock. Therefore, only the distributions before the crew entered the airlock and after entering the airlock upon returning from the EVA are presented below. These are designated as "Before EVA crew arrives" and "With EVA crew" respectively in the plots below.

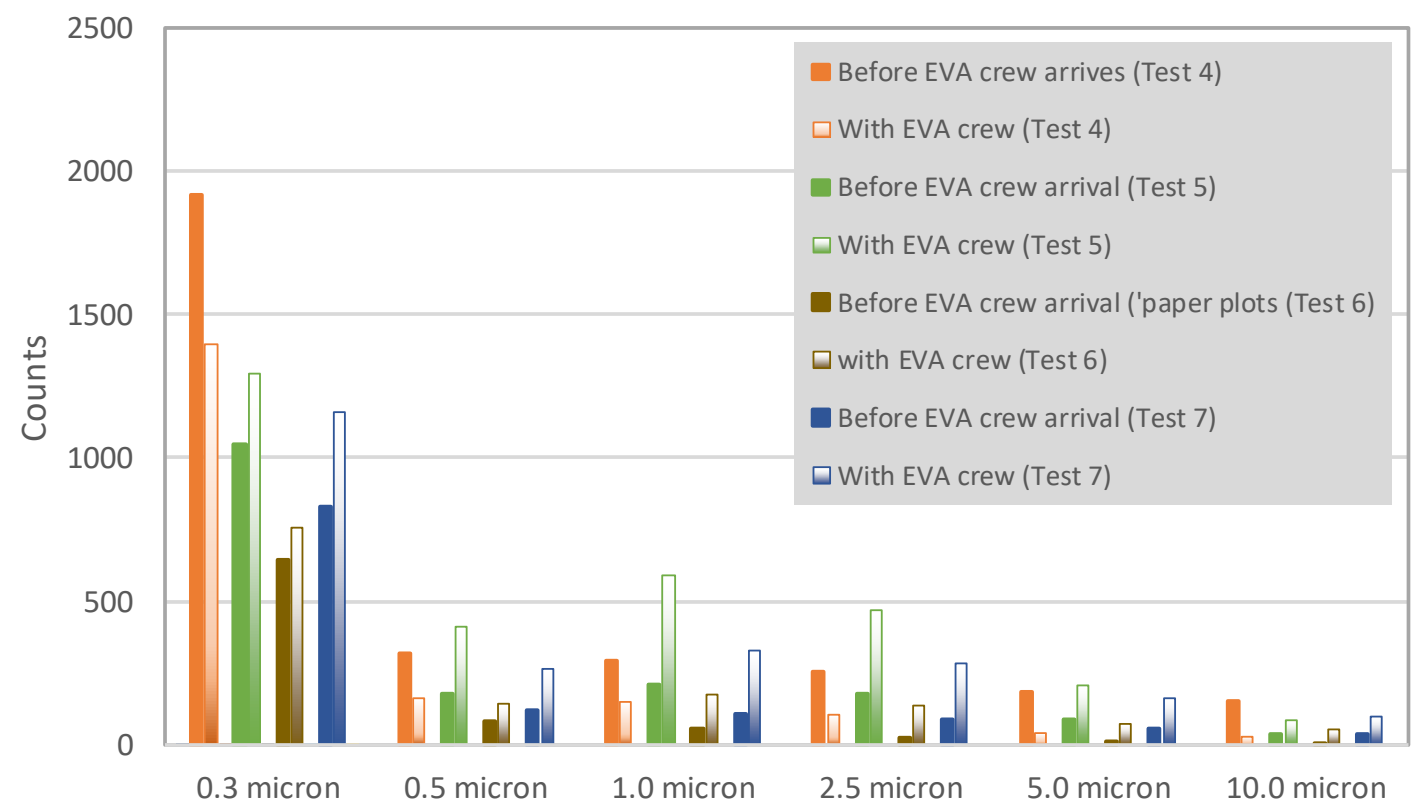

Figure 13: PSD of the airborne dust inside airlock before EVA crew arrival (solid color bars) and with EVA crew (gradient filled bars).

Figure 13 shows the comparison of the PSD of the dust inside the airlock before the EVA (solid color bars) and after the EVA crew enters the airlock (gradient filled bars). Each EVA is represented by a different color bar. For conciseness a subset of the EVA tests, Tests \# 4 through \#7, are plotted side by side. Test \#2 was omitted for reasons explained above, and Test \#3 was also omitted since it was conducted under similar conditions as Test \# 4. In all the EVA's the particle counts changed after the arrival of the crew into the airlock as the exposure to dust was different in each EVA. In Test \#5 "dirty work" was reported, while "physical activity" was conducted in Test \#6 and "dusty EVA" took place in Test \#7.

The PSD in Test \#4 showed a large quantity of 0.3 $\mu \mathrm{m}$ particle sizes but the counts in the larger size bins were similar to the other tests. After the crew arrived from the EVA, they entered the airlock, shook off the dust and, for tests indicated (Procedure VI), they ran the filtration unit. On every test, the OPC was run immediately after the crew exited the airlock into the habitat, followed by vacuum cleaning of the airlock. The PSD in Test \#4 shows a significant drop in particle counts of all sizes after the crew returns to the airlock. Tests \#5 through \#7 on the other hand show increases in particle counts in all sizes after the crew returned to the airlock.

\subsection{SFS Trapped Dust \\ 3.3.1. Post-EVA Airlock}

The SFS was used during the EVA airlock operations on Test \#5 to assess its performance in 
mitigating airborne dust in the airlock. It was operated when the crew entered the airlock after the EVA following the operation described in Section 2.2 (Procedure \#II). The corresponding data is presented in Figure 13 under Test \#5. It shows essentially no additional suppression of dust in comparison with the other airlock operation after the EVA. Also microscopic inspection of the filter media used during this test did not show by comparison any more dust collected in comparison to the other workspaces.

\subsubsection{MDRS Workspaces}

In Tests \# 8 - 10, the SFS was used in various workspaces in the MDRS to tests its filtration performance during crew activity. These workspaces included: the upstairs Work Area (Figure 14), Science Dome (Figure 16), and EVA Suit Room (Figure 18). The size and portability of the SFS facilitated the transporting and setting up of the unit in these workspace. Also, the three stages of filtration built into the SFS were suitable for capturing the anticipated range of particle sizes.

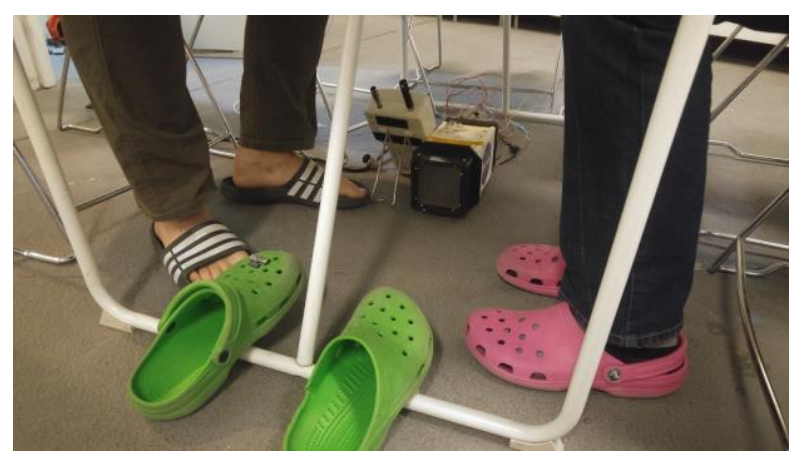

Figure 14: OPC and SFS location underneath the table of the upstairs work area for Test \#8 to measure ambient dust conditions in the residential sections of the habitable volume.

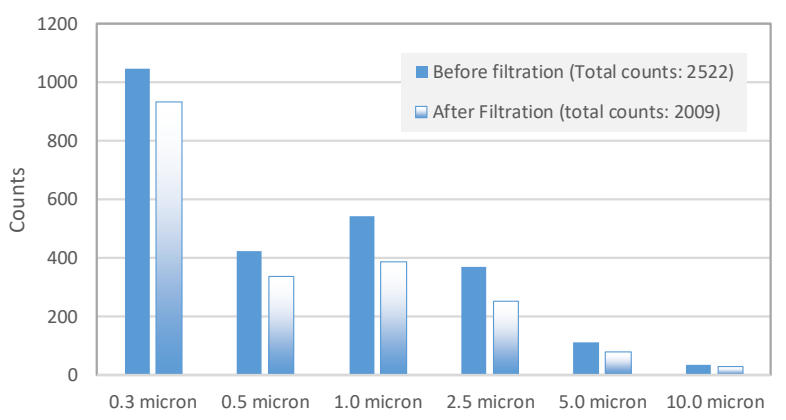

Figure 15: PSD in upstairs Work Area before and after filtration by the SFS.

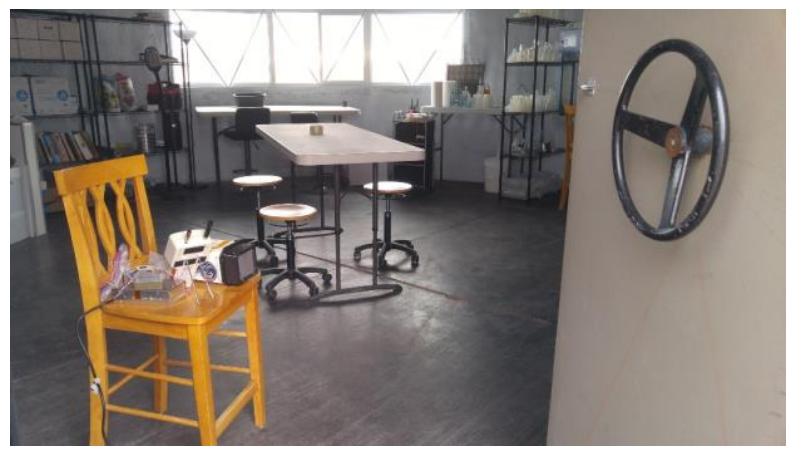

Figure 16: OPC and SFS location in the Science Dome for Test \#9 to measure ambient dust conditions.

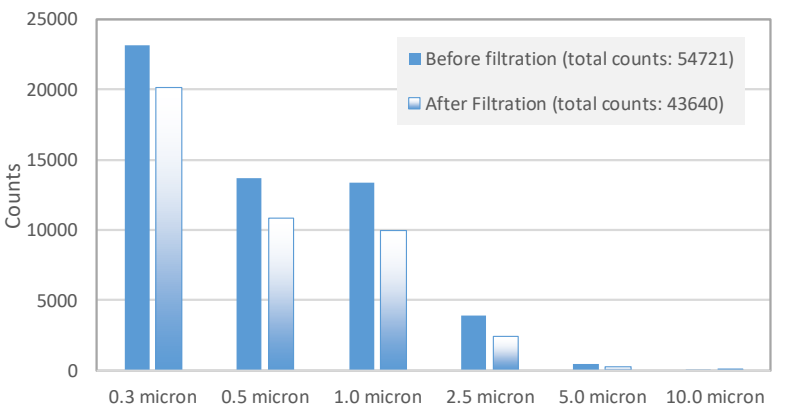

Figure 17: PSD before and after filtration in the Science Dome by the SFS.

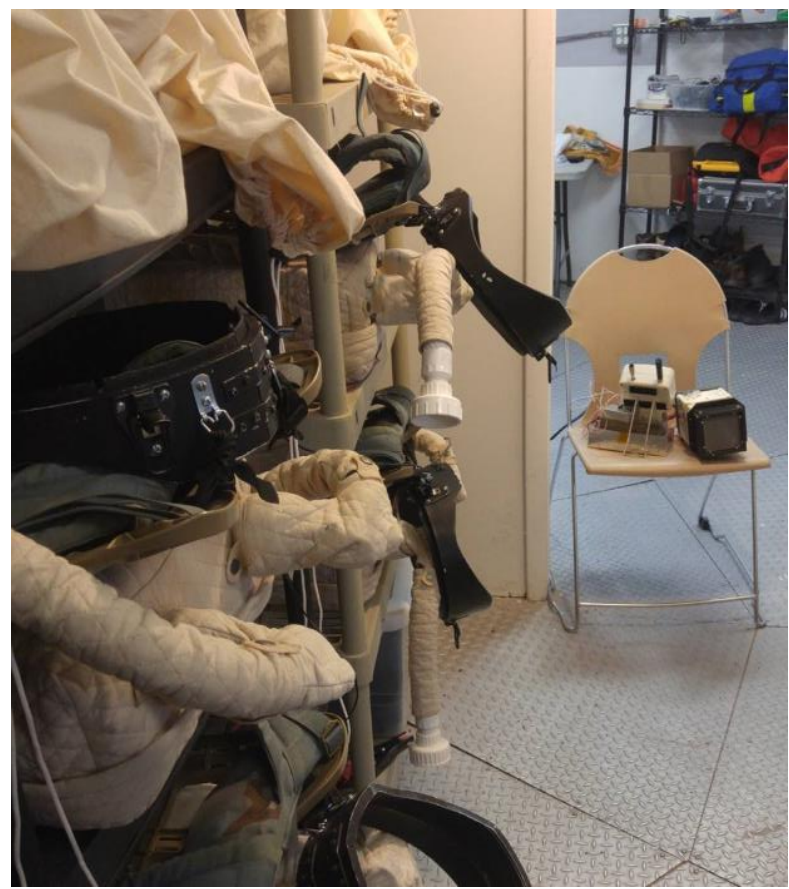

Figure 18: OPC and SFS location between EVA Prep Room (simulated spacesuit room) and Lower Deck lab / EVA preparation area for Test $\# 10$ to measure transitional dust conditions after the airlock. 


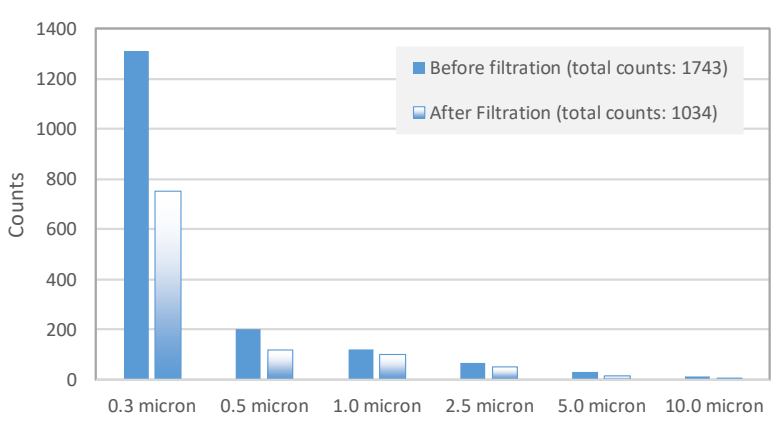

Figure 19: PSD before and after filtration in the EVA Suit Room by the SFS.

The field nature of the MDRS operations did not allow for the application of standard filtration testing techniques. Additionally, standard techniques are used to evaluate the performance of the media itself. Rather, the objective here was to determine the effectiveness of the filtration unit to reduce the concentration of airborne particles and improve air quality in the workspaces. To this end, the OPC was used to sample the particle environment before and after the filtering operation.

Table 3 provides the total airborne dust counts in the various workspaces in the habitat. The values in the last two columns are compared to show that there was a clear reduction in particles after filtering. Particle counts were reduced by $15 \%$ to $40 \%$ in the three cases. Also, Figure 15, Figure 17, and Figure 19 provide corresponding plots of the PSD data before and after filtration. These plots also show quite clearly the reduction in particle counts after filtration in all particle sizes.

Visual inspection of the screen, on the screen stage, the rubber bands, and on the impactor stage appeared to be relatively clean. If there was any dust, it was not apparently visible. Unfortunately, the weighing of these components prior to and after the tests were unreliable and showed virtually no weight gain. This could have been due to several factors. First, the size of particle these components were designed to capture could have been above the size of the dust particles brought into the habitat. Second, the small quantities of dust that could have collected competed with humidity effects when they were weighed. Lastly, there could have been a transfer to dust to stowage bags used to preserve and contain the samples.

\subsubsection{Outdoors}

One concern of ISRU systems is that the hardware residing on the planetary surface, and exposed the Martian atmosphere, may be impacted by dust storms even while not in operation. In order to assess this effect, the SMF was placed outdoors without the screen and impactor stages and subjected to windblown dust.
The inlet of the filter faced downward to simulate an optional ISRU atmospheric processor inlet orientation that would prevent dust build up from gravitational deposition in the Martian atmosphere. A windy day was chosen for the tests where the media was directly open to the outside environment.

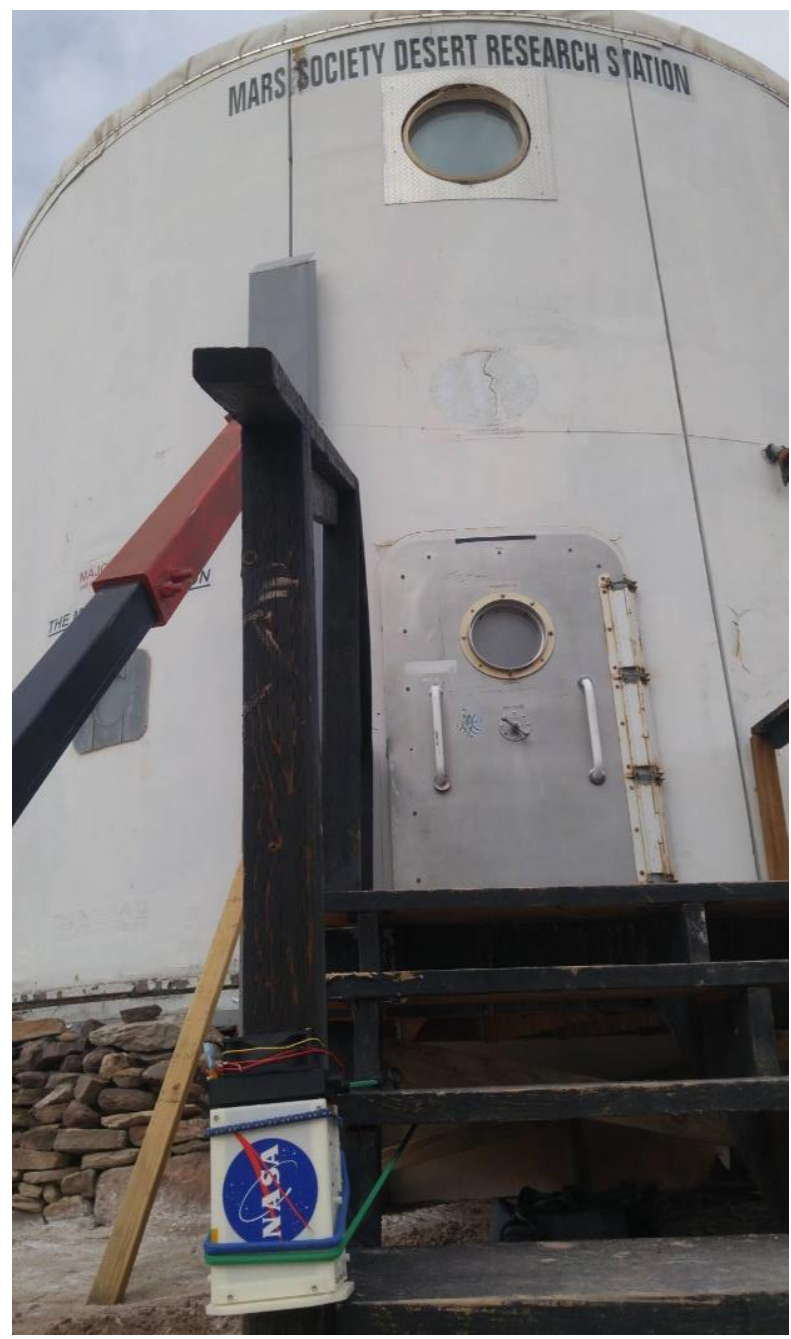

Figure 20: SFS' SMF location mounted outside of MDRS for Test \#11 to measure passive dust collection over two hours.

The following data was provided by the National Oceanic and Atmospheric Administration's (NOAA) National Climatic Data Center (NCDC) for United States Air Force (USAF) Station Number 724733, Weather Bureau Army Navy (WBAN) 23170, Hanksville, Utah, USA $(+38.417,-110.700$ and elevation +1355.1 feet) during the two-hour duration of Test \#10 on 10 February 2018 [24].

- $\quad$ Average Wind $25.6 \mathrm{~km} / \mathrm{hr}$ (15.9 mph)

- Average Wind Gust $37.8 \mathrm{~km} / \mathrm{hr}(23.5 \mathrm{mph})$

- Average Temperature $8.4^{\circ} \mathrm{C}\left(47.1^{\circ} \mathrm{F}\right)$

- Average Relative Humidity $36.4 \%$ 


\subsection{MDRS Crew 188 Operations}

Table 4 included the crew operation time to conduct this research totaling 1073 minutes. This 17 hours, 53 minutes over 9 days is approximately 2 hours per operational day.

A metric presented by Bos et al. [22] was contamination rate in terms of milligram per minute per crewmember (or crew). Table 4 presents these results by factoring how many crewmembers participated in the simulated EVA (3 or 4), the duration (totaling 2026 minutes in the field), the dust vacuumed $(71.1 \mathrm{~g})$, and thus calculating the contamination rate. The type of EVA or mode of transportation is indicated as well as the distance traversed (139.9 $\mathrm{km}$ or 86.9 miles total).

Table 4: EVA Summary of Key Metrics and Dust Contamination

\begin{tabular}{|c|c|c|c|c|c|c|c|}
\hline EVA & Type* $^{*}$ & $\begin{array}{l}\text { Crew } \\
\text { Size }\end{array}$ & $\begin{array}{c}\text { Duration } \\
\text { (min) }\end{array}$ & $\begin{array}{c}\text { Distance } \\
(\mathbf{k m})\end{array}$ & $\begin{array}{c}\text { Test } \\
\#\end{array}$ & $\begin{array}{l}\text { Vacuum } \\
\text { Dust (g) }\end{array}$ & $\begin{array}{c}\text { Contamination } \\
\text { Rate } \\
(\mathrm{mg} / \mathrm{min} / \mathrm{crew})\end{array}$ \\
\hline 1 & Rover $^{* *}$, Light Pedestrian & 3 & 57 & 1.8 & & - & - \\
\hline 2 & Rover, Light Pedestrian & 3 & 73 & 2.4 & & - & - \\
\hline 3 & Rover, Light Pedestrian & 3 & 160 & 19.2 & & - & - \\
\hline 4 & Hard Pedestrian & 3 & 188 & 4.5 & & - & - \\
\hline 5 & Rover, Light Pedestrian & 3 & 128 & 13.0 & & - & - \\
\hline 6 & Rover, Hard Pedestrian & 3 & 172 & 20.1 & & - & - \\
\hline 7 & Hard Pedestrian & 3 & 121 & 4.3 & 2 & 35.4 & 97.6 \\
\hline 8 & Hard Pedestrian & 3 & 142 & 4.3 & 3 & 4.6 & 10.8 \\
\hline 9 & ATV, Moderate Pedestrian & 4 & 158 & 13.5 & 4 & 4.4 & 6.9 \\
\hline 10 & Rover, Hard Pedestrian & 3 & 178 & 4.0 & 5 & 11.7 & 21.9 \\
\hline 11 & ATV, Light Pedestrian & 3 & 143 & 24.8 & & - & - \\
\hline 12 & Rover, Light Pedestrian & 4 & 118 & 4.0 & 6 & 11.9 & 25.2 \\
\hline 13 & Rover, Hard Pedestrian & 3 & 152 & 12.4 & & - & - \\
\hline 14 & Hard Pedestrian & 3 & 153 & 4.7 & 7 & 3.4 & 7.4 \\
\hline \multirow[t]{2}{*}{15} & ATV, Light Pedestrian & 3 & 83 & 6.8 & & - & - \\
\hline & TOTALS & & 2026 & 139.9 & & 71.1 & - \\
\hline
\end{tabular}

* Perceived difficultly using Blair et al. [25] and heart rate data from Kobrick et al. [10].

** The rover vehicles are two-person ATVs.

\section{Discussion}

\subsection{Post-EVA Dust Transported and Vacuumed in Habitat Airlock}

Estimates of the amount of dust tracked back into the airlock is a key design input for future vehicles and habitats. The MDRS project which is an analogue of a planetary Mars mission attempts to provide these estimates with the understanding that there are key differences in environmental conditions. However, the main mode of dust transfer was direct contact with the soil at the MDRS site which should be representative of the interaction with the Martian soil. While particle surface properties induced by the Martian environment, such as surface energy or charge, may affect this interaction, other properties or conditions such as gravity level should not be a factor. Therefore, it is with this understanding that we infer that the dust was mainly transferred through contact interactions between the suit fabric and tools and the soil as the crew worked at the site. A small percentage was deposited from airborne dust. Therefore, the data provided in Table 2 gives a quantitative assessment or approximation of the amount of dust that might be brought back during a planetary surface EVA.
The upper end of the contamination rate of dust collected by vacuuming, according to Table 4 , was 25.2 $\mathrm{mg} / \mathrm{min} / \mathrm{crew}$. For a three-hour EVA, for example, this would amount to about $4 \mathrm{~g} / \mathrm{EVA} / \mathrm{crew}$. This value is significantly lower compared to the Apollo derived estimate in Section 1.2. However, the Apollo estimate is a conservative value that accounts for all the dust collected on the EVA suit and equipment being brought back to the lander. It does not consider the dust that is lost when it is shaken off outside the spacecraft. Alternately, the vacuumed dust in the present data does not account for the dust that stays embedded in the EVA suit and equipment. Despite the lower dust intrusion rate found here, there is still cause for concern for even this amount of dust entering the airlock or habitat, a value that is sustained over a much longer duration than an Apollo-era mission.

Another outcome of this activity was the discovery that the portable vacuum cleaner started developing issue related to the dust exposure. The latching mechanism for the collection cup became harder to open, and therefore it became more challenging to release the collection cup from the main body of the vacuum cleaner. Also, the on/off switch was also harder to slide to the on position. Based on the observation that 
the dust was being introduced into vital clearances of the vacuum cleaner, it was not unlikely that the performance of the motor may also have been affected.

\subsection{Particle Counts of Airborne Dust}

\subsubsection{Dust Measurements Before Activities/Filtration}

The distribution of particle counts in the three main active areas were similar with the exception of greater counts in the range from $0.5 \mu \mathrm{m}$ to $2 \mu \mathrm{m}$ range in the general work area. The EVA Suit Room and the EVA Air Lock showed similar cleanliness levels with slightly higher levels of the smallest detectable $0.3 \mu \mathrm{m}$ sized particles and the counts significantly dropped for the larger sizes. This is a typical characteristic of indoor air quality. The large number of particle counts in the Science Dome is due to this structure not having an airlock and is exposed to the outside environment every time the door opens or closes. As a result, an excessive amount of particles of all sizes were found, but particularly concerning of fine particles below $1 \mu \mathrm{m}$.

\subsubsection{EVA Dust PSD}

The changes in particle counts after the crew returned to the airlock could be attributed to the varied activities during each EVA.

Table 4 provides a brief description, with relative intensity of the activities, performed during the EVAs. One differentiating activity was the use of the rover which was used on Tests \#5 and \#6 (i.e. EVA's 10 and 12). Rovers as observed terrestrially, and in the Apollo video archive, generate large quantities of the dust that deposits, even coats, suits and equipment as the wheels had slipped and kicked up dust. This seems to explain the correspondently large quantity of vacuumed dust in the airlock for these tests. The airborne particle counts also rose in these tests indicating that at least some of the particles collected during the EVA were redispersed in the airlock air from crew activity.

EVA 14 occurred in Test \#7. This test also shows a rise in particle counts after the airlock activities. "Hard Pedestrian" activity, in fact a long hike, was reported during this EVA. Although the smallest amount of dust seems to have been collected during this test, it shows that the activities in the airlock tended to re-entrain some particles into the airlock compartment that registered as increases in particle counts of all sizes. Test \#6 seemed to show the same trend (Test \#5 to be discussed in the next section). The reason for this is unclear but it seems that the activities in the airlock could have varied in these two cases. In addition, the composition and size distribution of the dust collected during the different EVA activities could have varied among these test cases.

\subsection{Filtration Unit Trapped Dust}

\subsubsection{Post-EVA Airlock}

The SFS was used in Test \#5 during the EVA crew return phase in the airlock. The data showed that the particle counts increased in the airlock in Test \#5 despite the use of the SFS. The increase in counts was similar to the the other airlock test cases where the SFS was not used. Therfore, there was essentially no additional suppression of dust realized by using the SFS. Again it is unclear why this was the case but the same explanation as in the previous section is offered.

\subsubsection{MDRS Workspaces}

As mentioned previously (section 2.1.1) the SFS unit provided for the MDRS tests was undersized for most of the workspaces. Despite this limitation, the data show that air filtration, even by a small portable filter, had a beneficial effect on air quality and general cleanliness. The filtration unit reduced the particle concentration in all the workspaces, with the exception of the airlock as explained above. In these cases, the rate of filtration was slightly larger than the dust generation source, in this case infiltration of outside air, resulting in the net particle reductions.

The most effective filtration took place in the Upper Deck work area. One factor in this case was the low baseline counts in the workspace prior to filtration, particularly the counts for particle sizes $0.5 \mu \mathrm{m}$ and larger which were significantly low. The net reduction of the larger particles after filtration was also not significant. Therefore, the overall reduction in particle counts was mostly attributed to the reduction in the 0.3 $\mu \mathrm{m}$ diameter particles. Only the Scroll media filter stage is able to remove this size of particle, and since it was equipped with HEPA media it did so very efficiently (99.97\% at a rated flow velocity). This could explain why the most significant reduction in particle counts took place in this workspace.

\subsubsection{Outdoors}

The effects of atmospheric winds and its potential to deposit dust on the SFM were assessed during Test \#11. The estimated winds were reported to average about 25 $\mathrm{km} / \mathrm{h}$ with gusts up to $37.8 \mathrm{~km} / \mathrm{h}$ during the two hours of testing. After the test, the media was removed from the filter housing and inspected under an optical microscope. A qualitative analysis showed that the media was not overwhelmed with dust and in fact appeared relatively clean. A sparse collection of particles was observed on the media shown in Figure 21. It seems that the lack of a forced flow through the filter, because it was not running, results in the absence of any of the main particle collection mechanisms that take place under nominal filtration operation. The only mechanism is deposition on the very surface of the filter as the wind induced flow passes over the surface of the 
filter. However, this limited interaction suppresses the overall amount of dust collected on the media. As the dust enters the inlet of the filter, particles do not preferentially deposit on the media versus other surfaces at the inlet. Therefore, these limiting effects can explain the relatively clean filter surface.

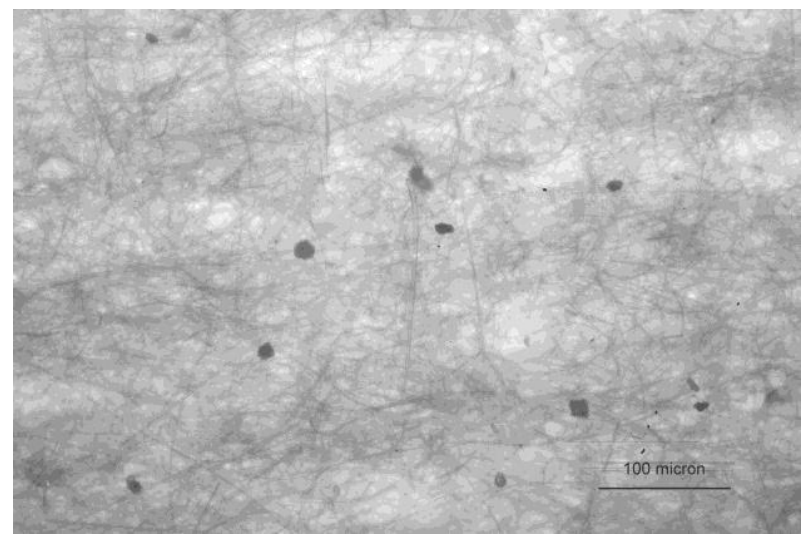

Figure 21: Particles trapped on the scroll media from the outdoor Test \#11.

\subsection{MDRS Crew 188 Operations}

Serendipitous investigations on Mars need to factor in available crew time. Adding a 2-hour daily task to a crewmember could be strenuous to their already packed schedule. Plenty of margin needs to be created over the span of a long duration spaceflight mission to ensure success and maintaining a balanced life-workload lifestyle at an extreme environment home away from home.

The dust contamination totals with respect to EVAs seemed reasonably low for the mission, but compared to expected Martian standards these values are quite high. Ventilation, filtration, dust mitigation technologies, and operational strategies need to be further examined to protect the crew and internal habitat equipment from particulate overload.

This work provided a strong example of how remote collaboration can be successful. Very clear instructions were provided for operating the equipment including a testing matrix and photos of the various internal parts. As mission equipment is built in similar circumstances, general question and answer sessions over emails could be replaced with videos. The video messages back and forth and digital manuals are the trend of the current YouTube generation, and with up to a 20-minute communication delay to Mars, this would be an ideal way to solve issues. Although, proper bandwidth will need to be available, which was extremely limited during Crew 188's mission at MDRS.

The inclusion of spare parts was important for this work as a specific fuse needed to be replaced while setting up the equipment for the first time. Extra samples bags were provided, hex keys/wrenches were included (just like Ikea), and an assortment of mostlikely-to-fail replacement parts. Advance repairs on Mars, which were not needed at MDRS for this work, would have required detailed instructions and would delay programs or data being collected.

\section{Recommendations for Future Testing}

This work created more research questions about the dusty environment for human spaceflight operations and what can be conducted in an analogue research station. MDRS' biggest strength for a simulated Mars mission is the location. Although similar research could be conducted in any desert household's primary entrance, the MDRS mission profile simulation rotations and field research (ranging from actual local measurements like geology that would be analogous to measurements taken in a desert on Mars, all the way to artistic expression and raw exploration wearing simulated surface spacesuits) makes the airlock use closer to the operations expected on a surface mission.

Some of the experiments conducted could be automated with data directly uploaded to a remote investigator. The OPC sampling is a good example where measurements could be triggered by mechanical activities such as the EVA Air Lock door opening / closing. With enough equipment, OPCs could be spread around the MDRS campus for a more intense study, and during an entire field session if crews are willing to data $\log$ their EVAs and other activities (crew handovers involve the overlapping crews moving gear in and out of the habitat).

There are several analogue stations all over the world that might be willing to participate. Habitats that are actually in a dusty environment would be excellent candidates. An air filtration unit could be added into their current infrastructure in several locations. Many stations do not have air handling or circulation, but the ones that do would be primary targets. That way filters could be added into the flow or a unit similar to the one in the study could be added. The system would involve basic maintenance for the crew to change the filter and send the old one to the investigators with timestamps and other data related to the activities.

Vacuuming the airlock was a relatively short additional task for the crew and had an interesting payoff of data collected with quantity of dust intrusion. This could also be continued across several simulations to get more data on expected dust. The simulations are obviously not low gravity and low atmospheric environments, but some of the dust transport mechanisms would be similar to actual mission profiles.

Data will continue to be processed including an analysis of dust samples returned, but just as important as recording metrics like particle size distributions, learning about how the samples can be obtained and processed are important for mission operations. This 
work gives a general approximation of what tasks are reasonable to add into a crew schedule. The amount of work was near the limit with some work being conducted after dinner, but it was the decision by the crew that this project was a high priority.

\section{Conclusions}

The MDRS Crew 188 mission provided a rather unique opportunity to investigate and test out mission scenarios and operations related to a Mars habitat surface mission. Dust issues were explored in order to gain a better perspective and understanding of the interactions with planetary dust, the level of dust exposure to the crew on EVA's, and the amount of dust entering the habitat. In addition, the effectiveness of employing local filtration in the various workspaces within the habitat, including the airlock, was also investigated. The amount of dust brought back by the crew and removed at the airlock varied on each EVA and was found to range between 3.4 to $11.9 \mathrm{~g}$ (with 35.4 $\mathrm{g}$ in the initial vacuuming). Airborne dust levels also varied prior to and upon returning to the airlock on each EVA. In most cases, the airborne particle counts in the range between $0.3 \mu \mathrm{m}$ and $10 \mu \mathrm{m}$ went up due to crew activity in the airlock at the end of the EVA. The use of the portable filter system, the SFS, showed that local filtering of the air in each of the internal habitat workspaces had a beneficial effect in the air quality. A test to investigate the effects of atmospheric winds on the face of the filter media for an ISRU application showed that the media was relatively clean after exposure with only a limited amount of dust particle deposition. Finally, the MDRS experience fostered many anecdotal suggestions to improve habitat infrastructure, including smart sensing within the Hab, as well as improvement and streamlining of crew activities and general operations.

\section{Acknowledgments}

The authors would like to acknowledge the EmbryRiddle Aeronautical University College of Aviation and Applied Aviation Sciences Department for their support in the establishment of the Spacesuit Utilization of Innovative Technology Laboratory (S.U.I.T. Lab). The authors also recognize the dedicated students of the S.U.I.T. Lab who helped support this project and its ongoing development.

Ryan L. Kobrick, Ph.D. acknowledges that this research was partially supported through Embry-Riddle Aeronautical University research funding (2017-2018 FIRST Award).

This research was partially supported by the EmbryRiddle Aeronautical University Faculty Research Development Program.

This project was supported by the National Aeronautics and Space Administration through the
University of Central Florida's NASA Florida Space Grant Consortium and Space Florida (2017-2018 Florida Space Research Program Award). The development of the SFS was supported by NASA's Advanced Exploration Systems (AES) division through the Life Support Systems and In-Situ Resource Utilization projects.

The authors thank the other crew members MDRS 188 (Renee Garifi, Dr. Sarah Jane Pell, Zac Trolley, Julia DeMarines, and Tatsunari Tomiyama) for their volunteer time and patience that allowed data to be recorded for this experiment.

\section{References}

[1] Gaier, J.R. (2007): "The Effects of Lunar Dust on EVA Systems During the Apollo Missions". NASA, Glenn Research Center, Cleveland, OH. NASA/TM2005-213610/REV1.

[2] Gaier, J.R., and Creel, R.A. (2005): "The Effects of Lunar Dust on Advanced EVA Systems: Lessons from Apollo". Presentation, Lunar Regolith Simulant Materials Workshop, NASA MSFC, 24 Jan 2005.

[3] Mcphee, J.C., and Charles, J.B. (2009): "Human health and performance risks of space exploration missions: evidence reviewed by the NASA human research program". Government Printing Office.

[4] Nemmer, A., Hoet, P.H.M., Vanquickenborne, B., Dinsdale, D., Thomeer, M., Hoylaerts, M.F., Vanbilloen, H., Mortelmans, L., and Nemery, B. (2002): "Passage of Inhaled Particles into the Blood Circulation in Humans". Circulation, American Heart Association, Inc. Brief Rapid Communications, 29 Jan 2002, pp. 411-414.

[5] Kobrick, R.L., Klaus, D.M., and Street, Jr., K.W. (2011): "Defining an abrasion index for lunar surface systems as a function of dust interaction modes and variable concentration zones". Special Volume of Planetary and Space Science "Lunar Dust Atmosphere and Plasma: The Next Steps". Vol. 59, Issue 14, Pp. 1749-1757. Elsevier. doi:10.1016/j.pss.2010.10.010

[6] Kobrick, R.L., Klaus, D.M., and Street, Jr., K.W. (2011): "Validation of proposed metrics for two-body abrasion scratch test analysis standards". J. WEAR. Vol. 270, Issues 11-12, 5 May 2011, Pp. 815-822. Elsevier. doi:10.1016/j.wear.2011.02.008

[7] Kobrick, R.L., Klaus, D.M., and Street, Jr., K.W. (2011): "Standardization of a volumetric displacement measurement for two-body abrasion scratch test data analysis". J. WEAR. Vol. 270, Issues 9-10, 4 April 2011, Pp. 650-657. Elsevier. doi:10.1016/j.wear.2011.01.026

[8] Kobrick, R.L., Klaus, D.M., and Street, Jr., K.W. (2011): "Developing Abrasion Test Standards for Evaluating Lunar Construction Materials". SAE 
International Journal of Aerospace. Vol. 4(1), Pp. 160-171 [Selected from ICES 2009 paper].

[9] Kobrick, R.L. (2010): "Characterization and Measurement Standardization of Lunar Dust Abrasion for Spacecraft Design and Operations”. Doctorate of Philosophy Dissertation, Aerospace Engineering Sciences Department. The University of Colorado at Boulder.

[10] Kobrick, R.L., Lopac, N., Schuman, J., French, J., and Tomiyama, T. (2018): "Increasing Spaceflight Analogue Mission Fidelity by Standardization of Extravehicular Activity Metrics Tracking and Analysis". 48th International Conference on Environmental Systems 2018, Session ICES403: Extravehicular Activity: Operations. Albuquerque, NM, USA. ICES-2018-191.

[11] Kobrick, R.L., Lopac, N., Schwartz, P., Schuman, J., Covello, C., French, J., Gould, A., Meyer, M., Southern, T., Lones, J., and Ehrlich, J.W. (2018): "Spacesuit Range of Motion Investigations Using Video and Motion Capture Systems at Spaceflight Analogue Expeditions and within the ERAU S.U.I.T. Lab". 48th International Conference on Environmental Systems 2018, Session ICES400: Extravehicular Activity: Space Suits. Albuquerque, NM, USA. ICES-2018-189.

[12] Agui, J.H. and Vijayakumar, R. (2013): "Development of an Indexing Media Filtration System for Long Duration Space Missions". 43rd International Conference on Environmental Systems, Vail, Colorado. AIAA-2013-3486.

[13] Agui, J.H. and Vijayakumar, R. (2015): "Characterization of a Regenerable Impactor Filter for Spacecraft Cabin Applications". 45th International Conference on Environmental Systems, Bellevue, Washington. ICES-2015-206

[14] Agui, J.H., and Mackey, J.R. (2009): "Development and Testing of a New NASA Lunar Dust Filtration Testing Facility". SAE Technical Paper. No. 2009-01-2358.

[15] Agui, J., Mackey, J., Vijayakumar, R., Seitz, T., and Bryg, V. (2010): "Investigation of the Filtration of Lunar Dust Simulants at Low Pressures". 40th International Conference on Environmental Systems. P. 6074. 2010.

[16] Agui, J.H., Vijayakumar, R., Perry, J.L., Frederick, K.R., and Mccormick, R.M. (2017): "Exploration Mission Particulate Matter Filtration Technology Performance Testing in a Simulated Spacecraft Cabin Ventilation System". 47th International Conference on Environmental Systems. ICES-2017-186

[17] Agui, J., Green, R., and Vijayakumar, R. (2018): "Development of a Multi-Stage Filter System for Cabin Ventilation Systems on the ISS and Future Deep Space Missions". 48th International Conference on Environmental Systems. ICES-2018-164.
[18] NASA Space Flight Human-System Standard, Volume 2: Human Factors, Habitability, and Environmental Health, NASA-STD-3001 Vol. 2 Revision A, 2015, pp. 42-43.

[19] Human Exploration of Mars Design Reference Architecture 5.0 Addendum \#2, NASA-SP-2009-566ADD2, National Aeronautics and Space Administration, March 2014.

[20] Agui, J.H., and Stocker, D.P. (2009): "NASA lunar dust filtration and separations workshop report." NASA/TM-2009-215821.

[21] Agui, J., Vijayakumar, R., and Perry, J. (2016): "Particulate Matter Filtration Design Considerations for Crewed Spacecraft Life Support Systems". 46th International Conference on Environmental Systems. Vienna, Austria. ICES-2016-93.

[22] Bos, B.J., Scott, D.J., and Metzger, S.M. (2011): "Habitat dust contamination at a Mars analog". Analogs for Planetary Exploration, W. Brent Garry, Jacob E. Bleacher. Geological Society of America Special Papers 2011;483;137-155.

[23] The Mars Society (2017): "Mars Desert Research Station". Website http://mdrs.marssociety.org. Last accessed 4 September 2018.

[24] NOAA's National Centers for Environmental Information (2018). Integrated Surface Database, Surface Data Hourly Global values for Hanksville, UT requested and received on 21 August 2018 from website: https://www.ncdc.noaa.gov/isd/data-access.

[25] Blair, S.N., Dunn, A.L., Marcus, B.H., Carpenter, R.A., and Jaret, P. (2001): "Active living every day". Human Kinetics; Champaign (IL). Data summary chart website: https://www.pacificu.edu/sites/default/files/document s/Energy\%20Expenditure\%20Chart.pdf. Last accessed 3 March 2018. 